
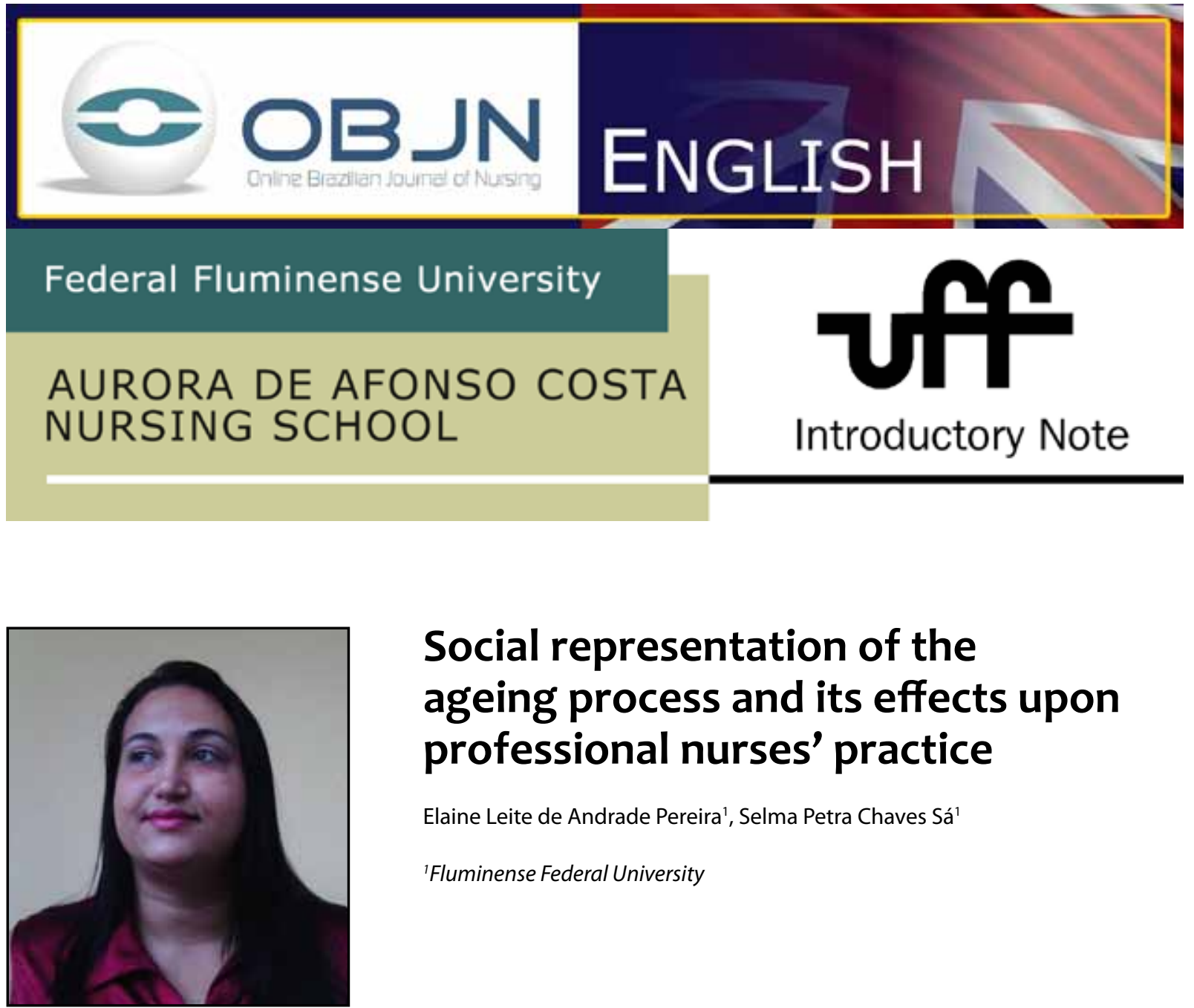

\title{
Social representation of the ageing process and its effects upon professional nurses' practice
}

\author{
Elaine Leite de Andrade Pereira', Selma Petra Chaves Sá \\ ${ }^{1}$ Fluminense Federal University
}

\section{ABSTRACT}

This is a Dissertation Research Project from the Science in Healthcare Master's Program at the Fluminense Federal University (UFF).

Aim: To discuss the social representations of the ageing process among professional nurses aged 60 years and over, and the effects it may have upon their practice.

Method: This a qualitative descriptive study based on the theory of Social Representations developed by Serge Moscovici. It will be conducted at Antonio Pedro University Hospital, and the participants will be nursing professionals. The data collected will be analysed using ALCEST software, which will facilitate the analysis of the group's collective discourse. This project has been approved by that institution's IRB.

Descriptors: Nursing; Manpower; Aged. 


\section{SITUATION PROBLEM AND ITS SIGNIFICANCE}

This is a Dissertation Research Project from the Science in Healthcare Master's Program at Fluminense Federal University (UFF). Improvement in the quality of life indicators indicate an increase in Brazilian life expectancy ${ }^{(1)}$. It has been increasingly common to see people over sixty years of age taking part in the labour market, including nursing professionals. Currently, there are about 1.5 million such individuals in Brazil $^{(2)}$. This historical moment draws attention to a new reality - the ageing process among nursing professionals. It is not difficult to see senior professionals giving assistance to senior patients. Therefore, it is important to have these senior professionals included in the labour market. The ageing process among nursing professionals has become an urgent issue that has to be addressed ${ }^{(3)}$. Taking into consideration the lack of studies on this theme, we believe this research should be of great relevance with regard to the field of nursing and also for related fields such as gerontology, administration and occupational health nursing, since the ageing process phenomenon affects all areas of nursing.

\section{GUIDING QUESTION}

What are the influences of the ageing process on the daily practice of nursing professionals?

\section{AIM}

Discuss the social representations of ageing for nursing professionals over 60 years of age, and the implications for their practice.

\section{ASSUMPTIONS}

This study assumes that the social representations held by senior professionals about their own ageing process influences their conceptions with regard to the limitations and possibilities for carrying out their work activities as members of a nursing team.

\section{METHOD}

This a qualitative descriptive study based on the theory of Social Representations developed by Serge Moscovici. It will be conducted at Antonio Pedro University Hospital and the participants will be composed of those nursing professionals (nurses, technicians and assistants) who agree to collaborate. This study has included any nursing professional, regardless of age and function, who is working at the hospital. The exclusion criteria are: nursing professionals working on night shifts; those who are away from work due to illnesses; and professionals with work restrictions for medical reasons. 48 is the estimated number of participants in the study, which will be conducted between March, 2012 and December, 2013. For data collection purposes, two focus groups have been chosen: the first one includes professionals who are at least 60 years of age, and the second one includes professionals up to 59 years of age. In the meetings, some questions are proposed in order to spark discussion on the topic and, after the discussion, participants draw up a summary of what has been discussed and considered to be true, based on common sense. This technique requires the presence of a moderator who is not there to interfere or elicit opinions, but to prevent participants from losing focus. There is also an observer who assists the moderator by recording the discussions. The technique also 
requires a calm and quiet environment to avoid external interferences. Each meeting's summary will have its corpus analysed using ALCEST 4.9 software (Analyse par Contexto d' um Ensemble de Segmentes de Texte). This software helps the researcher by pointing out the most relevant words in the interview transcriptions. Based on the ALCEST results, analysis will be based on the group's collective discourse and also on the theory of Social Representations developed by Serge Moscovici in order to give consistency to the data analysis. This project has been approved by the IRB of Antonio Pedro University Hospital, Fluminense Federal University, Niterói-RJ, on January $14^{\text {th }}, 2012$, under protocol no. CAAE: 11501712.0.0000.5243.

\section{REFERENCES}

1. Giron MN, Fonseca TC, Berardinelli et al. Repercussions of the climateric among nurses - an exploratory study. Online braz j nursing. 2012 [cited 2013 Mar 20]; 11(3): [about 5 p.] Available from: http://www.objnursing.uff.br/index.php/ nursing/article/view/3862.

2. Fundação Oswaldo Cruz [homepage on internet]. Escola nacional de saúde pública. Bem vindo a pesquisa perfil da enfermagem no Brasil [cited 2012 Oct 24]. Available from: http://www.ensp. fiocruz.br/perfildaenfermagem/.

3. Friedrich LA, Prasun MA, Henderson L, Taft $L$. Being a seasoned nurse in active practice. $J$ Nurs Manag [internet]. 2011 [cited 2013 Jan 15]; 19(7):897-905. Available from: http://www.ncbi. nlm.nih.gov/pubmed/21988437.
Project data: Science in Healthcare Master's Program.

Fluminense Federal University (UFF).

This study has not received financial support.

Examination Board: Professor Selma Petra Chaves Sá, PhD (President); Professor Célia Pereira Caldas, PhD (1 $1^{\text {st }}$ Examiner) and; Professor Simone Cruz Machado Ferreira, $\mathrm{PhD}$ (2 ${ }^{\text {nd }}$ Examiner). Dissertation from October 11th, 2012.

Authors'

Elaine Leite de Andrade Pereira: project preparation

Selma Petra Chaves Sá: Researcher's Mentor

Received: $17 / 02 / 2013$

Revised: 22/06/2013

Approved: $17 / 06 / 2013$ 